\title{
High School Students Modeling Behaviors During Engineering Design
}

\section{Mr. Tanner J Huffman, Purdue University}

Tanner Huffman is a research assistant and Ph.D. candidate in the Technology, Leadership and Innovation department at Purdue University. Additionally, he is an engineering and technology instructor at Richland Senior High School (7-12) in Johnstown, Pa. Tanner has experience writing integrated STEM curriculum and delivering professional development workshops on ITEEA's Engineering by Design program. His research interests include modeling and design in STEM education, as well as STEM teacher professional development.

\section{Prof. Nathan Mentzer, Purdue University, West Lafayette}

Nathan Mentzer is an assistant professor in the College of Technology with a joint appointment in the College of Education at Purdue University. Mentzer was a former middle and high school technology educator in Montana prior to pursuing a doctoral degree. He was a National Center for Engineering and Technology Education (NCETE) Fellow at Utah State University while pursuing a Ph.D. in curriculum and instruction. After graduation, he completed a one year appointment with the center as a postdoctoral researcher.

\section{Prof. Kurt Henry Becker, Utah State University - Engineering Education}

Kurt Becker is a professor in the Department of Engineering Education at Utah State University and the current director for the Center for Engineering Education Research (CEER) which examines innovative and effective engineering education practices as well as classroom technologies that advance learning and teaching in engineering. He is working on several National Science Foundation (NSF) funded projects including a project exploring engineering design knowing and thinking as an innovation in STEM learning. His areas of research include engineering design thinking, adult learning cognition, engineering education professional development and technical training. He has extensive international experience working on technical training and engineering projects funded by the Asian Development Bank, World Bank, and U.S. Department of Labor, USAID. Countries where he has worked include Armenia, Bangladesh, Bulgaria, China, Macedonia, Poland, Romania, and Thailand. He is currently a consultant on a USAID funded project that involves workforce development and enterprise competitiveness. He teaches undergraduate and graduate courses in the department. 


\section{High School Student Modeling Behaviors During Engineering Design}

\section{Rationale}

Mathematical modeling is an essential practice of engineering design ${ }^{1-6}$. Students in college engineering programs and expert engineers spend time modeling in the design process ${ }^{7}$. Additionally, high school technology and engineering education students spend time modeling during design challenges ${ }^{8}$.

While studies have found college students, experts and high school students are modeling, the National Academy of Engineering Committee on K-12 Engineering Education ${ }^{5}$ found that "Existing curricula do not fully exploit the natural connections between engineering and the other three STEM subjects". One of these connections, mathematical analysis and modeling, was nearly entirely absent. The committee stated, "very few curricula or professional development initiatives reviewed by the committee used mathematics in ways that support modeling and analysis" (p. 8). While research has indicated that students are spending time modeling, curriculum lacks structured modeling content. The conflict between student engagement in modeling, as reported by previous research, and the lack of a formalized curricular focus on modeling poses an interesting question: What kinds of modeling are students currently engaged in? The purpose of this study was to determine the amount of time students are engaging in different methods of modeling as defined by National Academy of Engineering. Furthermore, this study aimed to provide evidence about student modeling behaviors which may lead to more informed 
decisions about how engineering design can be used as a pedagogical strategy in science and mathematics instruction. The research questions driving this inquiry are:

1. What percentage of time do students engage in graphical, physical and mathematical modeling when presented with an engineering design problem?

2. As students are using mathematical modeling, what percentage of that time is spent for the purpose of describing, using functions or explaining system characteristics?

Results of this study will provide insight on how high school students engage in design and modeling when presented with a problem. As defined by Dym et al. ${ }^{2}$, engineering design is a thoughtful process. The processes of thinking and cognition are often invisible to both the students and the teacher ${ }^{9}$. This study will present evidence of how students allocate time in their thinking during problem solving.

\section{Framework}

Modeling is essential to learning and interpreting the environment around us. Studies in cognitive science described model-based reasoning as a way that learners make sense of the world ${ }^{10-11}$. Lehrer and Schauble ${ }^{11}$ built a case to support modeling as essential to learning, relating to humans as natural modelers. Modeling is the way we come to understand things that are unfamiliar to us. For example, someone may not understand how a thermostat operates. They can however, relate the functions of a thermostat to systems that they are familiar with such as a light switch. Modeling allows even the most complex understandings to be grounded in what is perceived. 
National Academy of Engineering and the International Technology and Engineering Educators Association define modeling as a product. As outlined in Engineering in K-12 Education ${ }^{5}$, modeling in engineering includes "any graphical, physical, or mathematical representation of the essential features of a system or process that facilitates engineering design" (p. 87). Modeling informs the important engineering process of optimization. Optimization is the balancing of competing or conflicting factors ${ }^{5}$. The International Technology and Engineering Educators Association recognizes analysis and modeling as essential to teaching engineering design, the principal problem solving method employed in engineering. "An optimum design is most possible when a mathematical model can be developed so that variations may be tested" ${ }^{12}$. A primary benefit of mathematical modeling is to enable analysis prior to expending resources to build and test in the physical world. Brophy et al. ${ }^{1}$ in the Journal of Engineering Education stated that, "from an engineering perspective this would include constructing conceptual prototypes of a system using mathematical models (equation, diagrams, graphs) and generating data to predict performance".

In addition to modeling as a product, modeling is also a process. Literature suggests that modeling, similar to design, can also be viewed as a process students engage in. As outlined by English and Doerr ${ }^{13}$, student evidence of modeling habits include the expression of explanations, predictions and descriptions. The modeling documentation principle, as outlined by English ${ }^{14}$, provides a framework to study modeling as a process. The modeling documentation principle identifies how students externalize their thinking and reasoning while drawing, making lists, and creating various representations of their 
design. These representations contain descriptions and explanations of the steps the students took to create their models ${ }^{14}$.

A detailed look at design scholarship can offer insight on how modeling habits can be measured. Williams and Gero ${ }^{15}$ stated, "there have been numerous cognitive studies of designers that have been aimed at elucidating design thinking behavior". Moreover, several researchers across various disciplines of engineering study design using verbal protocol analysis ${ }^{7,8,15-19}$. Verbal protocol analysis (VPA) is appropriate when the study demands the examination of an active process itself and not simply the process's results

${ }^{18}$. The utilization of the qualitative observation and verbal protocol analysis allows for the examination of student design in an authentic assessment environment ${ }^{7,8}$.

Using the National Academy of Engineering and International Technology and Engineering Educators Association's definitions ${ }^{5,12}$, student modeling behaviors are evident in graphical, mathematical and physical representations. In addition, as described by English and Doerr ${ }^{13}$, modeling evidence is apparent as the students engage in the design process to achieve descriptions, predictions and explanations.

\section{Research Method}

The research method was designed to answer the study research questions. This study employed video recorded observation during a design challenge. The method permitted coding of student time allocation. The following descriptive statistics are presented in this paper: 
1. Percentage of time high school students engaged in different modeling types (graphical, physical and mathematical).

2. Percentage of time high school students spent mathematical modeling to describe, create functions and explain design decisions.

This study explored an existing data set and focused specifically on modeling. While the original study ${ }^{8}$ reported the amount of time students engaged in modeling, how the students allocated their modeling time modeled remained unclear. All videos had previously been coded for essential elements of design thinking including modeling as outlined in Becker, Mentzer, Park and Huang ${ }^{8}$. This current investigation probed deeper into the sections segmented and coded as "Modeling". Modeling was determined by $\operatorname{Atman}^{7}$ as:

Detailing how to build the solution (or parts of the solution) to the problem. Applies to initial solution concepts as well as to the final design. (p. 367)

A coding scheme was created to offer insight into what types of modeling students are using and for what purpose. Modeling was coded into three main types as identified by the National Academies of Engineering ${ }^{5}$ and the International Technology Education Association ${ }^{12}$; graphical, physical, and mathematical (Table 1).

As coded by the researchers, graphical modeling is defined as both creating and interpreting any drawing or sketch. Additionally, graphical modeling included creating lists and adding drawing annotations. Physical modeling is defined as creating, 
referencing and interpreting physical objects as well as making spatial relationships to physical objects that may be available in the design area. Mathematical modeling is defined as estimating or calculating measurements including quantifying, action of using mathematics and interpreting mathematics to inform design decisions.

Table 1

Coding Modeling Type

\begin{tabular}{lll}
\hline Type & Coding Description & Student Example \\
\hline Mathematical & $\begin{array}{l}\text { Quantifying. } \\
\text { Action of using mathematics . } \\
\text { Result of a function that informs a } \\
\text { decision in the design. }\end{array}$ & $\begin{array}{l}\text { "If I need 3 feet around the slide as a } \\
\text { safety area, then I would need space at } \\
\text { least } 12 \text { feet wide. Six feet for each } \\
\text { side... (calculates the amount of space } \\
\text { needed of other equipment)" }\end{array}$ \\
Graphical & $\begin{array}{l}\text { Sketching, Drawing. } \\
\text { Interpreting drawings to make } \\
\text { decisions. } \\
\text { Creating list or notes. }\end{array}$ & $\begin{array}{l}\text { "I need to make sure someone else can } \\
\text { read this drawing. (re-draws a swing } \\
\text { set)" }\end{array}$ \\
Physical & $\begin{array}{l}\text { Creating, referencing and } \\
\text { interpreting physical objects } \\
\text { Spatial representation with } \\
\text { physical objects. }\end{array}$ & $\begin{array}{l}\text { "How big is a sidewalk? (uses hands to } \\
\text { estimate the size a sidewalk) Yeah. } \\
\text { That should be about the right size." }\end{array}$ \\
\hline
\end{tabular}

Due to the nature and importance of mathematical modeling in engineering, mathematical modeling was coded for modeling purpose areas identified by English ${ }^{14}$. English identified two purposes of modeling in the modeling documentation principle: description and explanation (Table 2). Mathematical descriptions include the quantifying of system parameters. Mathematical explanations include mathematical information that leads to design decisions. In addition to the framework described by English ${ }^{14}$, the National Academies of Engineering ${ }^{5}$ suggested that functions are critical elements of mathematical modeling. 
While mathematical functions often describe a set of variables, functions also represent relationships among designated variables. Functions were coded in this study to discriminate between students that were attempting to use mathematical equations but did not use the results to inform design decisions (explanations). Students who used functions demonstrated a more advanced understanding of mathematical modeling than simply describing quantities.

As coded by the researchers, mathematical modeling purposes are hierarchical in nature. Mathematical functions could not occur without the student first describing system parameters. A mathematical explanation could not occur without the completion of a mathematical function. As noted in Table 2, mathematical explanations are preceded by both mathematical descriptions and functions in order to inform a design decision.

Table 2

Coding Mathematical Modeling Purpose

\begin{tabular}{lll}
\hline Mathematical Usage & Coding Description & Student Example \\
\hline Description & $\begin{array}{l}\text { Quantifying } \\
\text { Function }\end{array}$ & $\begin{array}{l}\text { "So, the park is about } 50 \text { feet } \\
\text { wide." }\end{array}$ \\
& $\begin{array}{l}\text { The action of using mathematics. } \\
\text { design decisions directly. } \\
\text { Preceded by a mathematical } \\
\text { description(s). }\end{array}$ & $\begin{array}{l}\text { "Since the park is } 50 \text { feet wide } \\
\text { and } 100 \mathrm{feet} \text { long, that means I } \\
\text { have } 5,000 \mathrm{ft}^{2} . "\end{array}$ \\
& $\begin{array}{l}\text { Result of a function that informs a } \\
\text { decision in the design. Preceded } \\
\text { by a mathematical description(s) } \\
\text { and function(s). }\end{array}$ & $\begin{array}{l}\text { "With } 5,000 \mathrm{ft}{ }^{2}, \text { I should easly } \\
\text { have room for a couple slides, } \\
\text { monkeybars, swing sets and } \\
\text { maybe, a little kids area." }\end{array}$ \\
\hline
\end{tabular}


A graduate student and an undergraduate research assistant conducted the coding. The researchers developed a coding document, coded together and independently and discussed results in order to calibrate the coders. The researchers independently coded four videos ( $20 \%$ of the data set). Kappa value was then measured to establish inter-rater reliability. The Kappa values for each code are provided (See Table 3).

Table 3

Kappa Values

\begin{tabular}{lc}
\hline Coding Comparison & $\begin{array}{c}\text { High School Students } \\
(\mathbf{n}=\mathbf{2 0})\end{array}$ \\
\cline { 2 - 2 } & Kappa Value \\
\hline Graphical & 0.84 \\
Mathematical & \\
$\quad$ Description & 0.72 \\
$\quad$ Function & 0.74 \\
Explanation & 0.67 \\
Physical & 0.96 \\
\hline
\end{tabular}

\section{Description of Sample}

This study contained a subset of participants from a larger inquiry conducted by Becker et al. ${ }^{8}$, High School Student Engineering Design Thinking and Performance. The focus of their study was descriptive in nature and aimed to uncover the way high school students designed. According to Becker et al. ${ }^{8}$, "Fifty-nine participants from four states were asked to think out loud in a three hour design challenge which was video and audio recorded". The students engaged in an ill-defined engineering design problem. The problem was adopted from previous literature including Atman et al. ${ }^{7}$. The data collected for the project were video and audio recordings of the students participating in the design 
space, student design documents, demographics and interests, as well a post design problem interview. For more detailed information concerning the specific data collection methods, see Becker et al. ${ }^{8}$.

For this study, the researcher has taken a purposeful stratified sample of twenty students, selected based on demographics. The sample was stratified such that males and females were represented equally and white and non-white students were also equally represented.

\section{Results}

Previous research ${ }^{8}$ suggested that students spend $60.2 \%$ of their total design time engaged in modeling. In the subset of data presented in this paper, each of the twenty students spent time using mathematical and graphical modeling. The data indicated that half (10) of the students did not spend any time using physical modeling. Overall, the data suggested that students spent the majority of their modeling time (68\%) using graphical modeling, (36\%) of their total modeling time using mathematical modeling and $2 \%$ of their modeling time representing with physical modeling (see table 4 ). The average percentage may exceed one hundred percent because one thought may have been coded more than one code. For example, a student may have been using both graphical and mathematical modeling in the same segment.

Typical graphical modeling included sketching and drawing. Students would frequently spend long continuous portions of time engaging in drawing. Most students created a 
rough layout of their designs and then add detailed views and specifications. In mathematical modeling, students would typically create numbered lists, indicate a drawing's scale, and add dimensions to graphical representations. Physical modeling was not an anticipated element of this data set, as students were not presented with materials or tools for prototyping. However, physical representations did occur, including holding up a ruler to estimate and consider size.

\section{Table 4}

\section{Student Modeling Behaviors}

\begin{tabular}{lc}
\hline Modeling Type & $\begin{array}{c}\text { Percent of Total Modeling } \\
\text { time (SD) }\end{array}$ \\
\hline Graphical & $68(19)$ \\
Mathematical & $36(14)$ \\
Description & $23(14)$ \\
Function & $9(9)$ \\
Explanation & $4(4)$ \\
Physical & $2(3)$ \\
\hline
\end{tabular}

Note. As reported by Becker et. al ${ }^{8}$, the average time students spent designing was 91.7 minutes. The average time modeling was 54.4 minutes.

Mathematical modeling was of special interest in this research study as it aligns with the National Academy of Engineering's ${ }^{5}$ investigation of K-12 engineering curriculum. Results indicate that students spent time using mathematics during modeling. The data indicated that students spent the majority of their mathematical modeling time for the purpose of description (refer to Table 4). For example, students would use mathematics to quantify dimensions and calculate cost. Dimensions were typically guesses or estimates based on previous experience (example: the slide should be 5 feet high). These 
descriptions were rarely informed by functions, and it was also rare that students used these numbers to inform design decisions (such as using the dimensions to determine lumber needed or square footage or depth of soft surface material). While students spent time describing their ideas with numbers, they spent little time relating those numbers to each other with functions. Students who used functions generated a relationship describing an element of their design. As an example of a function, students might describe a platform that was five feet wide and five feet long, and then state that five times five is twenty-five square feet. The creation of functions represents a deeper level of understanding and frequently represented simple algebraic concepts including Pythagorean theorem, surface and volume calculations.

Students spent little time using mathematical modeling for the purpose of explanation. Of the twenty students in this study, three (3) students did not use mathematical modeling for the purpose of explanation at all. A typical example of explanation included the usage of data collected by a mathematical equation to inform design decisions. Many of the student explanations were very basic in nature, such as calculating the height of monkey bars to ensure safety if the children would fall. Only a few students created generalizable models that could be reused. One student created a model to calculate cost of a fence based on the parameter of the enclosed area. As the parameters changed, so did the overall cost of the fence. The student then made informed decisions about paint and lumber selection. 


\section{Implications for Educators}

While graphical and physical modeling are important types of modeling, mathematical modeling was specifically recognized as essential by the National Academy of Engineering ${ }^{5}$ and is absent in the curriculum their study reviewed. Mathematical modeling occurred in this study, but much less frequently than graphical modeling. While $36 \%$ of the total modeling time was mathematically based, only $4 \%$ of the total modeling time informed design thinking. Teachers should encourage students to use mathematics to improve their design work in addition to using mathematics to describe their ideas. Yet, teachers may struggle to identify resources as the National Academy of Engineering suggested. Therefore professional developers and curriculum designers should seek opportunities to provide guidance to teachers on implementing mathematical modeling and highlight the opportunities for mathematical modeling to inform decision-making.

\section{Implications for Future Research}

Under this study's framework, future research could derive what modeling behaviors are appropriate for high school students learning progression. While the research presented in this study recognizes the importance of different types of modeling, the developmentally appropriate amount of time spent creating and using those models remains undetermined.

Additionally, future research may develop, test and disseminate potential mathematical modeling instructional materials for high school technology and engineering education 
classrooms. The framework outlined in this paper could provide a common assessment tool to study impacts of curriculum materials.

A literature review of existing modeling pedagogical tools may provide high school technology and engineering teachers with suitable classroom interventions. One such intervention, modeling-eliciting activities (MEA), may provide teachers with a method to help students better understand mathematical modeling and analysis. MEAs have been studied in a variety of areas, including university freshman engineering ${ }^{20}$ and high school math courses ${ }^{21}$. "A Model-Eliciting Activity (MEA) is a real-world client-driven problem. The solution of an MEA requires the use of one or more mathematical or engineering concepts that are unspecified by the problem" 22 .

High school students spend time engaging in graphical, physical and mathematical modeling. Students spend the most of their time engaging in graphical modeling. While students also engage in mathematical modeling, students are rarely using mathematical modeling to inform design decisions. This study supports the findings presented by the National Academies of Engineering that mathematical analysis and modeling is absent from high school technology and engineering education classrooms. Further research concerning age appropriate modeling behaviors and developmentally suitable instructional materials may provide potential solutions to the issues posed by the National Academy of Engineering. 


\section{References:}

1. Brophy, S., Klein, S., Portsmore, M., \& Rogers, C. (2008). Advancing Engineering Education in P-12 Classrooms. Journal of Engineering Education, 97(3), 369-387.

2. Dym, C. L., Agogino, A., Eris, O., Frey, D., \& Leifer, L. (2005). Engineering design thinking, teaching, and learning. IEEE Engineering Management Review, 34(1), 65-65. doi:10.1109/EMR.2006.1679078

3. Moore, T., \& Diefes-Dux, H. (2004). Developing model-eliciting activities for undergraduate students based on advanced engineering content. 34th ASEE/IEEE Frontiers in Education Conference (pp. 461-466). Savannah, GA: IEEE. doi:10.1109/FIE.2004.1408557

4. Moussavi, M. (1998). Mathematical modeling in engineering education. Frontiers in Education Conference (Vol. 2, pp. 963-966). Tempe, AZ: Stipes Publishing L.L.C. Retrieved from http://ieeexplore.ieee.org/xpls/abs_all.jsp?arnumber=738891

5. National Academy of Engineering, \& National Research Council. (2009). Engineering in K-12 education: Understanding the status and improving the prospects. (L. Katehi, G. Pearson, \& M. Feder, Eds.). Washington, DC: The National Academies Press.

6. Steif, P. S., \& Pantazidou, M. (2004). Identifying the components of modeling through protocol analysis. Proceedings of the 2004 American Society for Engineering Education Annual Conference \& Exposition, Salt Lake City, UT

7. Atman, C. J., Adams, R. S., Cardella, M. E., Turns, J., Mosborg, S., \& Saleen, J. (2007). Engineering design processes : A comparison of students and expert practitioners. Journal of Engineering Education, 96(4), 359-379. doi:10.1002/j.2168-9830.2007.tb00945.x

8. Becker, K., Mentzer, N., Park, K., \& Huang, S. (2012). High school student engineering design thinking and performance. American Society for Engineering Education Annual Conference \& Exposition. San Antonio, TX: American Society of Engineering Education.

9. Collins, A., \& Brown, J. (1991). Cognitive apprenticeship: Making thinking visible. American Educator, 1-18. Retrieved from http://elc.fhda.edu/transform/resources/collins_brown_holum_1991.pdf

10. Johnson-Laird, P. N., Girotto, V., \& Legrenzi, P. (1998). Mental models: A gentle guide for outsiders. Sistemi Intelligenti, 9, 68-33. Retrieved from http://music.ucsd.edu/ sdubnov/Mu206/MentalModels.pdf

11. Lehrer, R., \& Schauble, L. (2000). Developing model-based reasoning in mathematics and science. Journal of Applied Developmental Psychology, 21(1), 39-48. doi:10.1016/S01933973(99)00049-0

12. International Technology Education Association. (2000). Standards for technological literacy: Content for the study of technology. Phi Delta Kappan (Vol. 82). Reston, VA: International Technology Association.

13. Doerr, H. M., and English, L. D. (2003). A modeling perspective on students' mathematical reasoning about data. Journal for Research in Mathematics Education, 34(2), 110-137.

14 English, L. D. (2010). Modeling students' mathematical modeling competencies. In R. Lesh, P. L. Galbraith, C. R. Haines, \& A. Hurford (Eds.), Modeling Students' Mathematical Modeling Competencies (pp. 287-299). Boston, MA: Springer US. doi:10.1007/978-1-4419-0561-1

15. Williams, C., Gero, J., \& Lee, Y. (2011). Exploring the effect of design education on the design cognition of mechanical engineering students. ASME IDETC Design and Design Education (pp. $1-8)$.

16. Gero, J. S. (n.d.). Generalizing design cognition research. Retrieved from http://mason.gmu.edu/ jgero/publications/2010/10GeroDTRS8Cognition.pdf

17. Kelley, T. R. (2008). Cognitive processes of students participating in engineering-focused design instruction. Journal of Technology Education, 19(2), 50-64. Retrieved from http://scholar.lib.vt.edu/ejournals/JTE/v19n2/kelley.html

18. Simon, H., \& Ericisson, K. (1993). Protocol analysis: Verbal reports as data (2nd ed.). Boston: MIT Press.

19. Turns, J., Atman, C. J., Adams, R. S., \& Barker, T. (2005). Research on engineering student knowing: Trends and opportunities. Journal of Engineering Education, 94(1), 27-40.

20. Diefes-Dux, H., Hjalmarson, M., Miller, T., \& Lesh, R. (2008). Model-eliciting for engineering education. In J. Zawojewski, H. Diefes-Dux, \& K. Bowman (Eds.), Models and modeling in 
engineering education: Designing experiences for all students (pp. 17-35). Rotterdam, the Netherlands: Sense Publishers.

21. C Lesh, R., \& Yoon, C. (2004). Evolving Communities of Mind - In Which Development Involves Several Interacting and Simultaneously Developing Strands. Mathematical Thinking and Learning, 6(2), 205-226. Retrieved from

http://www.tandfonline.com/doi/abs/10.1207/s15327833mt10602_7

22. Moore, T. J. (2008). Model-eliciting activities: A case-based approach for getting students interested in material science and engineering. Journal of Materials Education, 30(5-6), 295-310. 